\title{
Effects of peripheral nerve injury on parvalbumin expression in adult rat dorsal root ganglion neurons
}

Tom Medici ${ }^{2,3}$ and Peter J. Shortland ${ }^{1,2^{*}}$

\begin{abstract}
Background: Parvalbumin (PV) is a calcium binding protein that identifies a subpopulation of proprioceptive dorsal root ganglion (DRG) neurons. Calcitonin gene-related peptide (CGRP) is also expressed in a high proportion of muscle afferents but its relationship to PV is unclear. Little is known of the phenotypic responses of muscle afferents to nerve injury. Sciatic nerve axotomy or L5 spinal nerve ligation and section (SNL) lesions were used to explore these issues in adult rats using immunocytochemistry.
\end{abstract}

Results: In naive animals, the mean PV expression was $25 \%$ of $L 4$ or $L 5$ dorsal root ganglion (DRG) neurons, and this was unchanged 2 weeks after sciatic nerve axotomy. Colocalization studies with the injury marker activating transcription factor 3 (ATF3) showed that approximately $24 \%$ of PV neurons expressed ATF3 after sciatic nerve axotomy suggesting that PV may show a phenotypic switch from injured to uninjured neurons. This possibility was further assessed using the spinal nerve ligation (SNL) injury model where injured and uninjured neurons are located in different DRGs. Two weeks after L5 SNL there was no change in total PV staining and essentially all L5 PV neurons expressed ATF3. Additionally, there was no increase in PV-ir in the adjacent uninjured L4 DRG cells. Co-labelling of DRG neurons revealed that less than $2 \%$ of PV neurons normally expressed CGRP and no colocalization was seen after injury.

Conclusion: These experiments clearly show that axotomy does not produce down regulation of PV protein in the DRG. Moreover, this lack of change is not due to a phenotypic switch in PV immunoreactive (ir) neurons, or de novo expression of PV-ir in uninjured neurons after nerve injury. These results further illustrate differences that occur when muscle afferents are injured as compared to cutaneous afferents.

Keywords: Plasticity, Axotomy, Spinal nerve ligation, Dorsal root ganglion, Proprioceptor

\section{Background}

Peripheral nerve injury disconnects sensory and motor axons from their peripheral targets and results in the production of regeneration associated genes such as $\alpha$-tubulin, GAP43, CAP23, ATF3, and STAT3 that are important in the growth and functional recovery of damaged sensory and motor axons $[1,2]$. Primary sensory neurons also show considerable plasticity when subjected to peripheral nerve injury. For example, directly injured neurons can upregulate neurotransmitters such as NPY,

\footnotetext{
*Correspondence: p.shortland@uws.edu.au

1 School of Science and Health, Western Sydney University, Narellen Road,

Campbelltown, NSW 2560, Australia

Full list of author information is available at the end of the article
}

BDNF, galanin whilst adjacent uninjured neurons can increase their content of neurotransmitters such as substance P, CGRP, BDNF, galanin and ion channels such as TRPRV1 and P2X3 [3-5]. This plasticity is thought to contribute to the generation and maintenance of neuropathic pain $[3,6,7]$. However, the mechanisms that contribute to chronic pain syndromes are incompletely understood. Several different models have been developed to explore the contributions of primary afferents to chronic pain syndromes [3, 8, 9]. Most models employ injury to the sciatic nerve, a mixed peripheral nerve, or its branches. Interestingly, one study demonstrates the importance of muscle afferents to the pathobiology of nerve injury pain. When the gastrocnemius (muscle) or 
tibial (mixed) or sural (cutaneous) nerve was sectioned, mechanical and thermal hypersensitivity only occurred in nerve injuries involving muscle afferents [10].

The phenotypic responses of muscle afferents to nerve injury have been relatively little studied. In the DRG, muscle afferents are generally identified by their size, neurotrophic factor dependence, or their expression of particular neurotransmitters or proteins [11-18]. Retrograde tracing experiments show that muscle afferents are both myelinated and unmyelinated [16]. Muscle nociceptors are generally small and contain high levels of the neuropeptide CGRP $[15,16]$ whereas muscle spindle afferents are generally large-sized, myelinated fibres that express carbonic anhydrase, or the calcium binding proteins calretinin, calbindin, neurocalcin or parvalbumin [19-25]. Some of these markers, however, are not specific to muscle afferents, as they are also found in skin afferents [26-28]. Whilst parvalbumin is generally regarded as a reliable marker for proprioceptive afferents [22, 23], genetic studies have revealed that, by itself, it is not a selective marker of muscle proprioceptors nor a marker of muscle afferent nociceptors [26, 29].

Relatively few studies have assessed the effects of nerve injury on parvalbumin expression. Most of the published literature concerns injuries to branches of the trigeminal $[30,31]$ or sciatic $[22,32,33]$ nerves and the general consensus appears to be that injury has little effect on parvalbumin expression in the affected DRGs. One possible reason for this is that a phenotypic change in expression in injured versus uninjured afferents occurs, such that parvalbumin expression is decreased in injured neurons and increased in uninjured neurons. As the sciatic nerve contains axons originating in the L4-6 DRGs, afferents from these ganglia are only partially affected by peripheral nerve injury. By assessing changes only in parvalbumin expression with this model it is not possible to tell whether a phenotypic change has occurred. Phenotypic switching in primary afferents is known to occur in nerve injury models $[3,5,34]$. This issue can be explored by using the regeneration associated transcription factor ATF3 [35]. ATF3 is not expressed in the DRG nuclei of uninjured neurons but is rapidly induced in all injured neurons following peripheral axotomy or spinal nerve injury [35]. By quantitatively assessing the number of co-labelled ATF3 and parvalbumin neurons after sciatic nerve injury, it is possible to determine the presence or absence of a phenotypic switch. A second, and more clear-cut, method involves using a spinal nerve ligation and section injury [36]. This essentially injures all axons in the L5 DRG but leaves axons in the adjacent L4 DRG largely unaffected $[5,34,35]$. Changes can then be compared by assessing the numbers of PV cells in the two adjacent ganglia.
Therefore, the aim of this study is to test the hypothesis that peripheral nerve injury induces a phenotypic switch in subpopulations of PV-ir neurons in the dorsal root ganglia.

\section{Results}

Naive animals

PV-ir was expressed primarily in medium to large-sized DRG neurons (Fig. 1a). Quantification of expression in the L4 and L5 ganglia is shown in Table 1. Similar percentages were expressed in both ganglia and there was no statistical difference between the ganglia $\left(t_{7}=0.255\right.$, $\mathrm{P}>0.5$, 2-tailed test).

CGRP-ir was predominantly expressed in small-sized DRG neurons with some expression in medium- and large-sized DRGs (Fig. 1b). Quantification of CGRPir expression in the naive L5 ganglia was $48.3 \pm 1.9 \%$ $(\mathrm{N}=6)$. Colocalisation between PV-ir and CGRPir within the L5 DRG was negligible $(1.9 \pm 1.9 \%)$ and, when present, was restricted to the large-sized neurons.

\section{Sciatic nerve axotomy}

The expression of PV-ir in the L4 and L5 ganglia 2 weeks after sciatic nerve axotomy is detailed in Table 1 . The percentage expression in these ganglia was not significantly different from naïve ganglia (L5 DRG: $F_{2,11}=1.800$, P > 0.1, L4 DRG: $t_{7}=0.766, \mathrm{P}>0.5$, 2-tailed test). The PV-ir in axotomised neurons was observed in the medium to large-sized cells of the ganglia, identical to that seen in naive ganglia.

It is possible that the unchanged percentage of PV-ir after sciatic nerve axotomy reflects a phenotypic switch in neurons such that injured neurons lose immunoreactivity and uninjured ones start to express PV de novo. To explore this possibility colocalisation with ATF3 was performed (Fig. 2). ATF3-ir was expressed in $50.7 \% \pm 4.9$ of ipsilateral L5 DRG and $43.4 \% \pm 7.0$ of the ipsilateral L4 ganglion cells, and these values were was not significantly different from each other $(\mathrm{p}=0.21)$.

If a phenotypic switch occurs, one might expect to see little or no colocalisation with ATF3 after injury. However, this was not the case (Fig. 2). Analysis of double labelled sections showed that $23.7 \% \pm 3.7$ of PV-ir cells (range 16-30 \%) expressed ATF3 in the injured ipsilateral L4-5 ganglia. By itself, this result is insufficient to determine if a phentotypic switch is occurring.

\section{Spinal nerve ligation}

To better explore the possibility of a phenotypic switch after injury, the experiment was repeated using the L5 spinal nerve injury model, which essentially damages all of the axons of the L5 ganglion neurons whilst leaving most of the axons of the adjacent L4 DRG intact [5, 34]. 

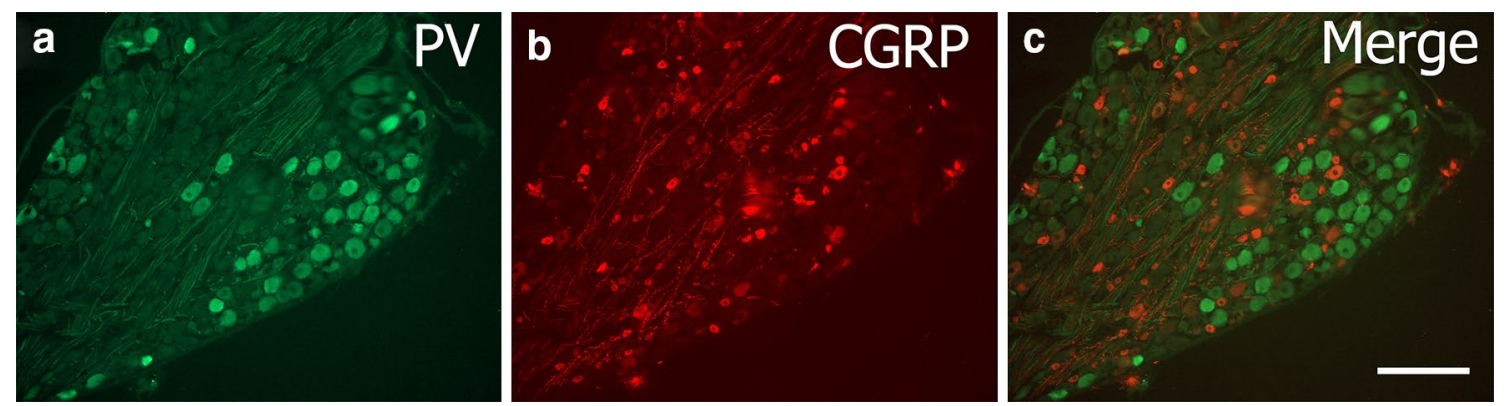

Fig. 1 An example of parvalbumin and CGRP staining in naïve L5 DRG. a shows PV-ir (green), b shows CGRP-ir (red) staining and c is the merged image showing essentially no overlap between these populations. Scale bar $100 \mu \mathrm{m}$

Table 1 Percentage expression of parvalbumin in L4 and L5 DRGs in naïve and sciatic axotomy groups

\begin{tabular}{lll}
\hline & L4 DRG & L5 DRG \\
\hline Naïve $(\mathrm{N}=6)$ & $25.7 \% \pm 1.8$ & $25.1 \% \pm 1.8$ \\
2 week sciatic nerve axotomy $(\mathrm{N}=5)$ & $23.1 \% \pm 1.9$ & $21.7 \% \pm 1.5$ \\
\hline
\end{tabular}

The L4 and L5 ganglia from both ipsilateral and contralateral sides to the L5 SNL were stained (Fig. 3) and quantified for immunoreactivity to PV, ATF3, and CGRP (Table 2). The mean percentage expression of PV-ir in the ipsilateral injured L5 ganglia was not significantly different from naive animals $\left(F_{1,8}=0.266, \mathrm{P}>0.5\right)$ or the contralateral side $\left(F_{1,8}=2.126, \mathrm{P}>0.1\right)$ or the ipsilateral L4 DRG $\left(F_{1,8}=0.103, \mathrm{P}>0.5\right)$.

ATF3-ir in the contralateral L5 DRG was negligible (Table 2). In the injured L5 ganglia, ATF3-ir was found in almost all cells (Fig. 3), confirming the completeness of the lesion. Essentially, nearly all PV-ir neurons coexpressed ATF3 (Table 2). In the ipsilateral L4 ganglia the average ATF3-ir was low (Table 2) but significantly more than the contralateral side $\left(F_{1,6}=7.242, \mathrm{P}=0.036\right)$, with the occasional PV-IR cell showing ATF3 staining (Fig. 3).

CGRP staining was essentially absent from the L5 DRG neurons in the injured ganglion, although some axonal staining could be detected (Fig. 4). The characteristic punctate staining in the cell cytoplasm that is normally present (Fig. 4b) is absent in the ipsilateral L5 DRG (Fig. 4a). In the ipsilateral L4 ganglia the average CGRPir was not significantly different from naïve animals (Table 2; p > 0.5) and colocalisation of CGRP in PV-ir cells was $0.6 \pm 0.3 \%$.

\section{Discussion}

PV is often used as a marker of a subpopulation of (muscle) proprioceptive afferents, comprising 10-33\% of cells in spinal and trigeminal ganglia [11, 19, 22, 23, 33, 37, 38].
This study found that $25 \%$ of naïve rat L4-5 DRGs were PV-ir, consistent with these earlier reports. By itself, PV is not an exclusive marker of muscle proprioceptive afferents, as it is also expressed in Pacinian corpuscles, Merkel cells and lanceolate endings of cutaneous afferents [26]. Thus, since retrograde tracing from muscles was not used in this study we cannot be sure that all PV-ir cells in this study are muscle proprioceptors. However, only around $1.5 \%$ of L4-5 PV-ir DRG cells arise from skin afferents [22] and a recent anatomical study showed that $27 \%$ of lumbar dorsal root fibres were positive for $\alpha 3$ $\mathrm{Na}+/ \mathrm{K}+$ ATPase, a specific marker of muscle afferents [13]. The similarity in percentage expression of PV-ir and $\alpha 3 \mathrm{Na}+/ \mathrm{K}+$ ATPase implies that PV-ir afferents should express this ATPase transporter, although this awaits confirmation. Together, these suggest that the vast majority of PV-ir cells are muscle proprioceptors.

Whilst PV is almost exclusively expressed in large diameter muscle afferents [22], CGRP is expressed in both large and small diameter muscle afferents [16]. The large-sized neurons correspond to the group I-II muscle spindle and Golgi tendon organ (proprioceptive) afferents, whereas group III-IV afferents are small diameter muscle afferents associated with muscle metabolic responses, blood vessel innervation, sensations involved during exercise and muscle pain [39]. Colocalisation studies suggest that PV is found in DRGs that may also contain calbindin, carbonic anhydrase (CA) and cytochrome oxidase $[11,20]$. This is consistent with the proposed role of PV in facilitation of fast, repeated, afferent firing of fast twitch muscles [40, 41]. CGRP is also expressed in large-sized DRG cells but the colocalisation of PV and CGRP was minimal in the present study, confirming earlier studies $[23,42]$.

\section{Plasticity of primary afferents after injury}

DRG cells show considerable plasticity in response to peripheral nerve injury. Following injury, peptides such 

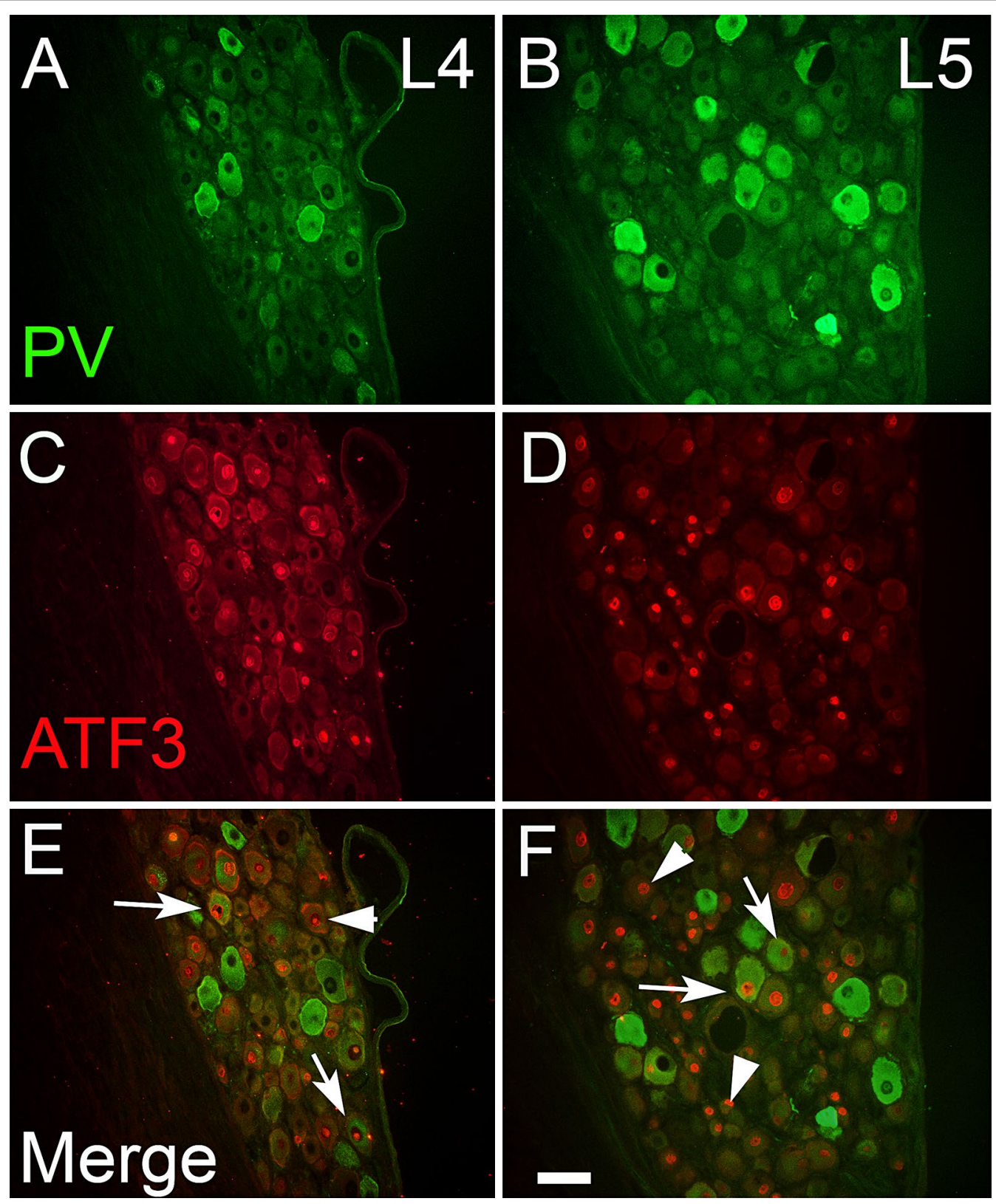

Fig. 2 Parvalbumin (green) and ATF3 (red) staining in the ipsilateral L4 (A, C, E) and L5 (B, D, F) ganglia of rats with sciatic nerve axotomy 2 weeks previously. Arrows indicate double-labelled cells, whilst arrowheads denote cells only expressing ATF3. Both injured and uninjured cells express PV-ir. Scale bar $75 \mu \mathrm{m}$

as CGRP and substance $P$ are often down regulated in injured DRGs whilst other peptides such as galanin and neuropeptide $\mathrm{Y}$ are upregulated (reviewed by $[4,6])$. This de novo expression also occurs in adjacent uninjured DRGs [3].Only a few studies have assessed the effects of axotomy on PV afferents and these have largely been in the trigeminal system [31, 43, 44]. The trigeminal system is different from the spinal system in that PV-ir is expressed in both the trigeminal ganglion $(\mathrm{Vg})$, which contains cell bodies of cutaneous afferents and the mesencephalic nucleus (Vmes), which contains cell bodies of muscle afferents. When the inferior alveolar nerve was sectioned no change in PV numbers occurred in the $\mathrm{Vg}$ [31]. When the masseter nerve was sectioned there was a significant drop in PV-ir cells in Vmes between 4 and 14 days post injury [43]. However, as there was no baseline control values for PV-ir in Vmes, there is no certainty as to whether there was an overall decrease in expression 

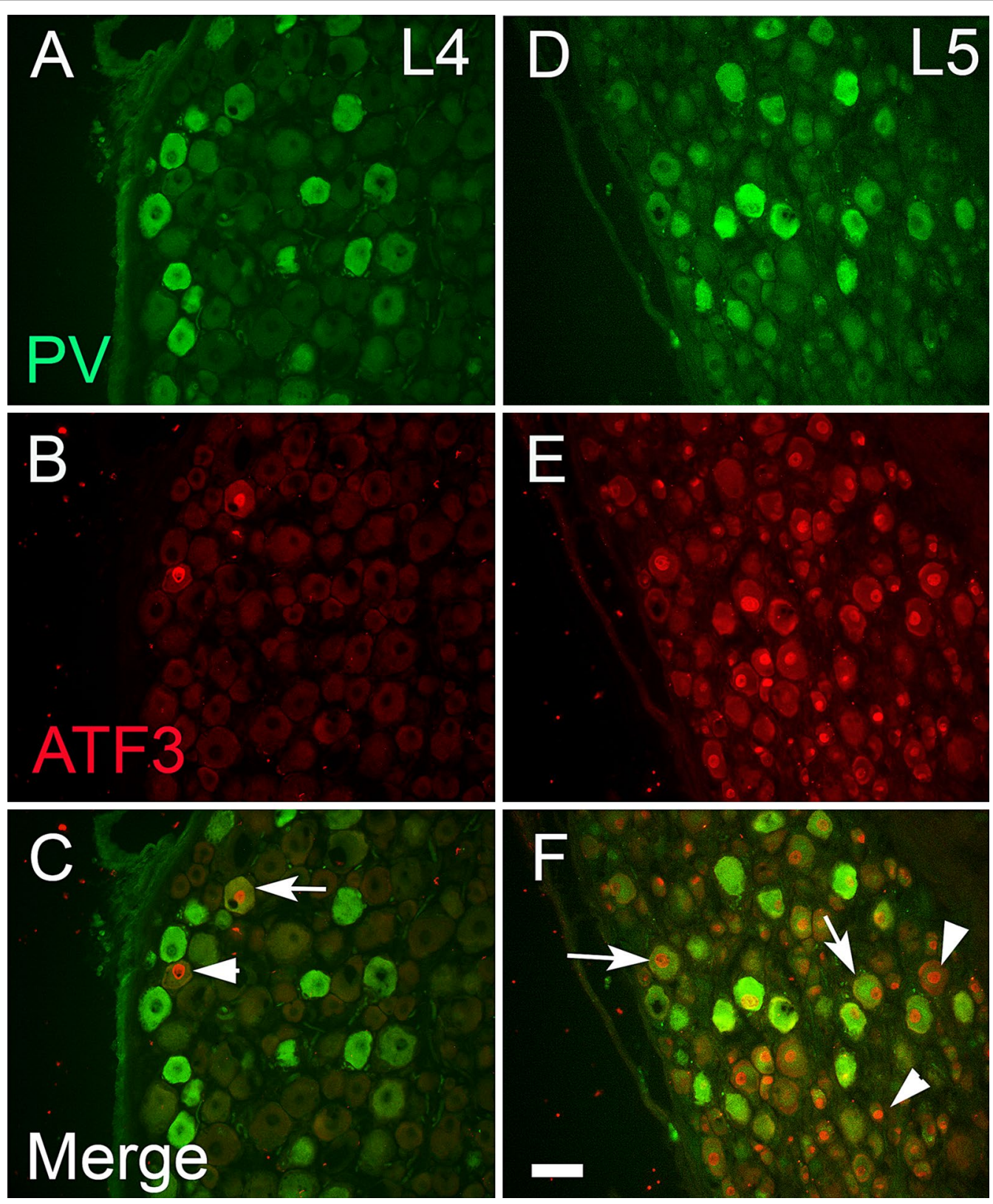

Fig. 3 Parvalbumin (green) and ATF3 (red) staining in the ipsilateral $L 4(\mathbf{A}, \mathbf{C}, \mathbf{E})$ and $L 5(\mathbf{B}, \mathbf{D}, \mathbf{F})$ ganglia 2 weeks after $L 5$ spinal nerve ligation and section. Arrows denote examples of double-labelled cells; arrowheads denote examples of cells that only express ATF3. Almost all PV-ir cells were ATF3-ir in the L5 ganglion (arrows). Very few ATF3 cells were seen in L4 DRG. Scale bar $75 \mu \mathrm{m}$

Table 2 Effects of L5 spinal nerve ligation on percentage expression of different neurochemical parameters in the L4-5 DRG neurons 2 weeks after injury

\begin{tabular}{llll}
\hline $\mathbf{N = 5 )}$ & $\begin{array}{l}\text { L4 DRG } \\
\text { ipsilateral }\end{array}$ & $\begin{array}{l}\text { L5 DRG } \\
\text { ipsilateral }\end{array}$ & $\begin{array}{l}\text { L5 DRG } \\
\text { contralateral }\end{array}$ \\
\hline Parvalbumin & $23.0 \% \pm 1.2$ & $22.8 \% \pm 0.9$ & $22.2 \% \pm 0.8$ \\
CGRP & $44.5 \% \pm 1.7$ & 0 & $48.3 \% \pm 2.7$ \\
ATF3 & $2.8 \% \pm 0.9$ & $92.8 \% \pm 0.9$ & $0.3 \% \pm 0.1$ \\
\hline
\end{tabular}

by day 14 or whether there was an increase which normalised by day 14 . Alternatively, since PV is expressed in periodontal ligament afferents in the Vg [44], the difference between the two studies may reflect a difference in the response to injury of cutaneous mechanoreceptors versus muscle afferents.

In spinal DRGs, previous injury studies suggest that PV numbers either did not change [22] or were transiently decreased [32]. These studies were at early 

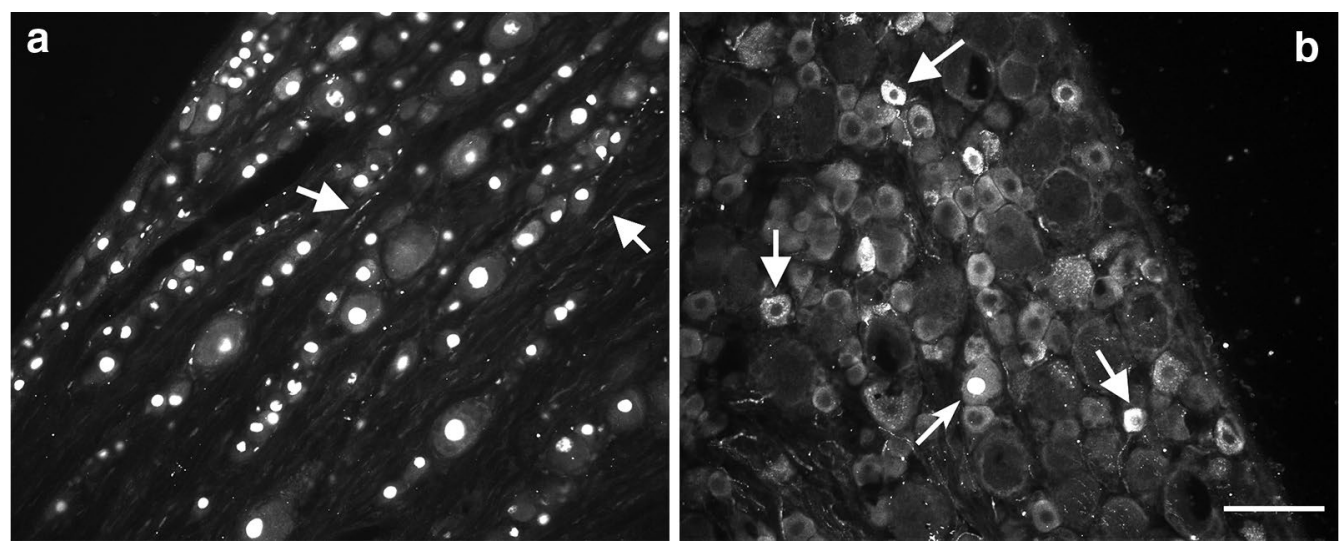

Fig. 4 An example of ATF3 and CGRP staining in L5 DRGs 2 weeks after spinal nerve section. a L5i ganglion showing no CGRPr in ATF3 positive cells. CGRP axons were visible in the tissue (arrows) but the characteristic punctate staining in the cell cytoplasm is absent. b Contralateral ganglion showing many CGRP-ir cells (arrows). The curved arrow shows an example of an ATF3+/CGRP- cell. Scale bar $=50 \mu \mathrm{m}$

time-points when changes in neurochemical phenotype are only beginning to start [45]. Additionally, these previous studies did not consider the possibility of a phenotypic switch between injured and uninjured neuronal populations [3, 34]. This study examined changes at only 1 time point, 2 weeks after injury. Whilst it is possible that changes occurred before then, previous studies have shown that peak changes in DRG neurotransmitter staining occur at 2 weeks post injury $[4,46]$. Moreover, the percentage expression of ATF3 positive injured neurons remains unchanged over the first month after both types of nerve injury [5, 47]. Therefore, analysing co-labelling at this time point should maximise the changes of observing any differences as a result of injury. By using the SNL model and co-labelling ATF3 with PV, this study unequivocally showed that injury did not produce a phenotypic switch in PV staining from injured to uninjured neurons, and that PV-ir in DRGs is not regulated by nerve injury. This contrasts with small diameter neurons, whose phenotype changes with nerve injury due to the loss of target derived trophic factors like NGF and BDNF [46].

These results are also consistent with the lack of change of other markers in large-sized DRG neurons after injury: NF200, a marker of large myelinated afferents, is unchanged $[45,46]$ and $\alpha 3 \mathrm{Na}+/ \mathrm{K}+$ ATPase is reported not to change in spinal nerve injury up to 1 week post injury [17]. Neuronal p75 levels in muscle afferents are unchanged after injury [48] as is TRPV2 expression [49]; TRPV2 has been shown to be colocalised to some muscle afferents [50]. CA, which is also localised to muscle proprioceptive afferents, also shows no change in expression after sciatic nerve injury [51]. Lastly, the lectin soybean agglutinin (SBA) is unchanged after injury for at least
3 months in the DRG [52]. SBA is expressed in about $50 \%$ of small- and medium-sized muscle DRG cells [18] and is extensively co-expressed with CGRP but not CA [53]. It is possible that PV levels may decline later on, in a fashion similar to SBA and CA, but further studies are required to verify this; however, we see no change in PV expression at 4 weeks after sciatic injury (Shortland and Medici, unpublished observations).

Does this mean that large-sized, presumed, muscle proprioceptive afferents are incapable of phenotypic plasticity? Evidence suggests that at least some medium-large diameter muscle afferents upregulate NPY and galanin and BDNF [10, 54, 55]. Indeed, Zhou et al. [10] demonstrated that BDNF was increased in axotomised muscle but not skin afferents and this was critical to produce neuropathic pain. Most recently, Fukuoka et al. [56] have demonstrated an increase in Nav1.7 in axotomised putative proprioceptors in DRGs and the gracile nucleus following spinal nerve ligation. Taken together, these studies suggest that different neurotransmitters and receptors may be differentially regulated within single cells. CGRP and substance $P$ have also been reported to increase in large sized DRG neurons [57, 58]. Whilst mRNA levels have confirmed this, protein expression studies have been less convincing. The majority of studies examining SP or CGRP-IR changes in the axotomised DRG have used immunofluorescence cytochemistry $[5,45,59]$ and failed to confirm the earlier reports based on mRNA or $\mathrm{DAB}$ histochemistry, suggesting differential sensitivity based on methodology. In this study, CGRP-ir was almost completely depleted in the L5 DRG somas after spinal nerve injury, and even if a few large cells increase CGRP protein expression these results suggest it is not in PV-ir afferents. 


\section{Potential roles for parvalbumin after nerve injury}

$\mathrm{PV}$ is a calcium binding protein responsible for controlling the levels of intracellular calcium ions [60]. Calcium is vital for cell function and its concentration must be strictly regulated: too little and the cell cannot perform functions such as neurotransmitter release; too much and cellular mechanisms of apoptosis are triggered [61]. Support for PV's ability to increase cell survival comes from animal studies of ALS pathogenesis. PV is only expressed in subsets of motoneurons such as Onuf's nucleus and the oculomotor nuclei [62-65], areas often spared from cell death in ALS patients. When PV was genetically overexpressed in motoneurons in vitro, they were better able to withstand concentrations of extracellular calcium associated with excitotoxic cell death and showed an increased ability to survive compared to their wild-type counterparts [66].

Peripheral nerve injury also causes cell death as a result of loss of trophic support $[67,68]$ that is differentially distributed with respect to peripheral target, with a preference for loss of cutaneous versus muscle afferents [48, 69-71]. PV-ir cells are known to be trkC positive $[12,26]$ and levels of NT3 in peripheral tissues are higher at birth then they are in the adult. It is possible that PV-ir cells maintain their trophic support from the CNS where levels are higher [72]. Supporting this, neonatal nerve crush depletes PV-ir cells from the DRGs [73]. Given that adult axotomy does not deplete neuronal p75 and that BDNF is upregulated in trkC neurons $[48,55]$, it is probable that PV-ir cells are trophically supported by BDNF released from BDNF baskets that surround trkC cells containing p75 in an autocrine manner [51]. In contrast, injured small sized, cutaneous DRGs, lose p75 neuronal staining and do not upregulate BDNF after injury $[10,48]$ and so may be more vulnerable to death.

Nerve injury also generates spontaneous and ectopic activity that is associated with axotomised and intact muscle, but not skin, afferents [39, 74, 75] that starts within hours, lasts many weeks and is predominantly associated with A-fibres. As PV-ir is associated with fast twitch muscles it is tempting to speculate that it is these fibres that may be spontaneously active in the DRG. However, electrophysiological data suggests that the very large-sized DRG cells are not spontaneously active [75]. As more than $80 \%$ of axotomised muscle afferents express BDNF after injury [10] it is likely that many of the PV-ir afferents will express BDNF. Since BDNF is a potent neuromodulator of neuronal activity [76,77], it is BDNF that is the major contributor to pain states from muscle afferents [10] whereas PV may be important for the survival of neurons after injury. An additional, or alternate, possibility is that spontaneous discharges may affect sensory processing through up-regulation of Nav1.7 in axotomised muscle afferents at the level of the gracile nucleus [56].

\section{Conclusions}

These results show that in two different models of peripheral nerve injury, the percentage of PV in DRG cells remains unchanged compared to naive or contralateral DRGs. Furthermore, by using ATF3 as a marker of injured neurons and by using the spinal nerve ligation and section model $[5,34]$, they unequivocally demonstrate, for the first time, that this is not the result of a phenotypic switch in expression from injured to uninjured cells, as numbers of PV-ir cells in the intact L4 DRG and the injured L5 DG remain unaltered. Therefore, PV positive afferents do not show the same phenotypic plasticity that is characteristic of other neuronal subpopulations such as nociceptors $[4,46]$. These results further highlight the differential responses of muscle as compared to cutaneous afferents after peripheral nerve injury.

\section{Methods}

All experimental procedures were carried out in accordance with the UK Scientific Procedures Act (1986) and guidelines set out by the International Association for the Study of Pain guidelines for the care and use of animals [78].

\section{Surgery}

Sixteen adult Wistar rats (250-350 g) were used and split into 3 groups: naive $(n=6)$, sciatic nerve axotomy $(\mathrm{n}=5)$ and L5 spinal nerve ligation and section $(\mathrm{n}=5)$. All surgical procedures were carried out on the left side under sterile conditions as described in detail previously $[3,43]$. Briefly, the sciatic nerve was exposed at mid-thigh level, ligated with a 4-0 nylon suture and cut distal to the suture. For the spinal nerve injury, the L5 spinal nerve was exposed, ligated with a 4-0 nylon suture and the nerve cut distal to it. Following nerve section, the wound was closed and topical antibiotics applied to the wound site to prevent post-operative infection. All animals survived post-operatively for 2 weeks before perfusion.

Rats were terminally anaesthetised and perfused with saline followed by $4 \%$ paraformaldehyde (dissolved in $0.1 \mathrm{M}$ phosphate buffer, pH7.4) fixative. The L4 and L5 DRGs were removed bilaterally and post-fixed for $2 \mathrm{~h}$ before being cryoprotected overnight in $30 \%$ sucrose dissolved in phosphate buffered saline (PBS) solution. Ganglia were embedded in OCT (VMR International) and frozen prior to sectioning for immunohistochemical staining. 


\section{Immunocytochemistry}

Longitudinal sections $(8-10 \mu \mathrm{m})$ were cut on a cryostat and thaw-mounted onto Superfrost plus (VWR International) slides. Each adjacent section was separated by $50-100 \mu \mathrm{m}$. Sections were blocked in $10 \%$ normal donkey serum (Chemicon) for an hour and then incubated with goat anti-parvalbumin (1:8000, Swant, PVG214 RRID:AB_10000345) for $24 \mathrm{~h}$ at room temperature. Slides were then washed 3 times in PBS before incubation with fluorescein isothiocyanate (FITC)-conjugated donkey anti-goat IgG (Jackson ImmunoResearch, 1:400) for $1 \mathrm{~h}$.

In double labelling studies, sections were first incubated in PV for $24 \mathrm{~h}$, washed in PBS and then incubated with rabbit anti-ATF3 (1:200, Santa Cruz SC-188 RRID:AB_2258513), or rabbit anti-CGRP (1:2000, Affinity Research Products Ltd., UK) for $24-48 \mathrm{~h}$ at room temperature. Following three PBS washes, sections were then incubated in donkey anti-rabbit $\mathrm{Cy} 3$ (1:800, Jackson ImmunoResearch, USA) for $2 \mathrm{~h}$ at room temperature. In some slides, sections were also counterstained with $100 \mu \mathrm{g} / \mathrm{ml}$ DAPI (4,6-diamino-2-phenylindole, Sigma, UK) to reveal neuronal nuclei. All slides were cover-slipped with 8:1 glycerol:PBS solution. Controls for double labelling included reversing the order of the antibodies or omission of the primary or secondary antibodies. The characteristics and validity of these antibodies have been described previously $[5,46,79]$.

Slides were examined on a Leica fluorescence microscope. For each animal, and each DRG, a minimum of 500 neuronal profiles (cells with clearly visible nuclei, confirmed by DAPI staining) were counted from 3 to 5 randomly chosen sections and the immunoreactivity (ir) was expressed as a percentage of all cells counted. PV-ir cells were considered positive if the intensity of staining was clearly above background staining seen in smallsized neurons in the same section.

In double labelled sections, the percentage of PV-ir cells expressing either ATF3-ir or CGRP-ir was assessed by switching between the DAPI, FITC and TRITC filter blocks. Photographs were taken with a Hamamatsu digital C4742-95 camera and plates assembled using Adobe Photoshop v5. The quantification was performed in a non-blinded fashion, since levels of ATF3-IR would give clues to which group was being quantified.

\section{Statistical analysis}

All data is expressed as mean \pm standard error of the mean. One-way ANOVA tests or independent samples $\mathrm{t}$ tests were carried out (using SPSS 16 statistical package, SPSS Inc., Chicago, IL, USA) to assess whether there was a statistically significant difference between groups; $\mathrm{p}<0.05$ was considered significantly different.

\section{Abbreviations}

ir: immunoreactivity; ATF3: activating transcription factor 3; PV: parvalbumin CGRP: calcitonin gene related peptide; FITC: fluorescein isothiocyanate; Cy3: cyanine dye 3; TRITC: tetrarhodamine isothiocyanate; DAPI: 4,6-diamino2-phenylindole; DRG: dorsal root ganglion; IgG: immunoglobulin.

\section{Authors' contributions}

PS performed surgery, perfusions and tissue removal. TM performed all histology, data quantification, statistical analysis, and image capture. Both authors contributed to manuscript writing. Both authors read and approved the final manuscript.

\section{Author details}

${ }^{1}$ School of Science and Health, Western Sydney University, Narellen Road, Campbelltown, NSW 2560, Australia. ${ }^{2}$ Centre for Neuroscience and Trauma, Blizard Institute, Barts and The London School of Medicine and Dentistry, Queen Mary University of London, Newark Street, London E1 2AT, UK. ${ }^{3}$ Present Address: Queens Hospital, Romford, Essex RM7 OAG, UK.

\section{Acknowledgements}

Dr Medici was supported by the Worshipful Company of Tallow Chandlers during this study. This work was funded by internal research funds associated with the Neuroscience intercalated BSc. Degree at Queen Mary University of London.

\section{Competing interests}

The authors declare that they have no competing interests.

Received: 30 July 2015 Accepted: 7 December 2015

Published online: 16 December 2015

\section{References}

1. Fagoe ND, Attwell CL, Kouwenhoven D, Verhaagen J, Mason MRJ. Overexpression of ATF3, c-Jun, STAT3 and Smad1 promotes regeneration of the central axon branch of sensory neurons but without synergistic effects. Human Molec Genet. 2015. doi:10.1093/hmg/ddv383.

2. Gordon T, Tetzlaff W. Regeneration associated genes decline in chronically injured motoneurons. Eur J Neurosci. 2015. doi:10.1111/ejn.13070.

3. Fukuoka T, Noguchi K. Contribution of the spared primary afferent neurons to the pathomechanisms of neuropathic pain. Mol Neurobiol. 2002;26:57-67.

4. Hökfelt T, Zhang X, Wiesenfeld-Hallin Z. Messenger plasticity in primary sensory neurons following axotomy and its functional implications. Trends in Neurosci. 1994;17:22-30.

5. Shortland PJ, Baytug B, Krzyzanowska A, McMahon SB, Priestley JV, Averill SA. ATF3 expression in L4 dorsal root ganglion neurons after L5 spinal nerve transection. Eur J Neurosci. 2006;23:365-73.

6. Costigan M, Scholtz J, Woolf CJ. Neuropathic pain: a maladaptive response of the nervous system to damage. Ann Rev Neurosci. 2009;32:1-32.

7. Millan M. Induction of pain: an integrative review. Prog Neurobiol. 1999;57:1-164.

8. Colleoni M, Sacerdote P. Murine models of human neuropathic pain. Biochimica and Biophysica Acta. 2010;1802:924-33.

9. Sorkin LS, Yaksh TL. Behavioural models of pain states evoked by physical injury to the peripheral nerve. Neurotherapeutics. 2009;6:609-19.

10. Zhou $\sqcup$, Ren WJ, Zhong Y, Yang T, Wei XH, Xin WJ, Lui CC, Zhou LH, Li $Y Y$, Liu XG. Limited BDNF contributes to the failure of skin afferents to produce a neuropathic pain condition. Pain. 2010;148:148-57.

11. Carr PA, Nagy I. Emerging relationships between cytochemical properties and sensory modality transmission in primary sensory neurons. Brain Res Bull. 1993;30:209-19.

12. Copray JC, Mantingh-Otter IJ, Brouwer N. Expression of calcium-binding proteins in the neurotrophin-3-dependent subpopulation of rat embryonic dorsal root ganglion cells in culture. Dev Brain Res. 1994;81:57-65.

13. Dobretsov M, Hastings SL, Sims TJ, Stimers JR, Romanovsky D. Stretch receptor-assocaited expression of a3 isoform of the $\mathrm{Na}+, \mathrm{K}+-$-ATPase in rat peripheral nervous system. Neuroscience. 2003;116:1069-80. 
14. Lawson SN, Perry MJ, Prahabakar E, McCarthy PW. Primary sensory neurons: neurofilament, neuropeptides and conduction velocity. Brain Res Bull. 1993;30:239-43.

15. Molander C, Ygge J, Dalsgaard CJ. Substance P-, somatostatin, and calcitonin gene related peptide-like immunoreactivity and fluoride resistant acid phosphatase-activity in relation to retrogradely labelled cutaneous, muscular and visceral sensory neurons. Neurosci Letters. 1987;74:37-42.

16. O'Brien C, Woolf CJ, Fitzgerald M, Lindsay RM, Molander C. Differences in the chemical expression of rat primary afferent neurons which innervate skin, muscle or joint. Neuroscience. 1989;32:493-502.

17. Parekh A, Campbell AJM, Djouhri L, Fang X, McMullan S, Berry C, et al. Immunostaining for the a3 isoform of the $\mathrm{Na}+/ \mathrm{K}+-$-ATPase is selective for functionally identified muscle spindle afferents in vivo. J Physiology. 2010;588(21):4131-43.

18. Perry MJ, Lawson SN. Differences in expression of oligosaccharides, neuropeptides, carbonic anhydrase and neurofilament in rat primary afferent neurons retrogradely labelled via skin, muscle or visceral nerves. Neuroscience. 1998;85:293-310.

19. Antal MF, Freund TF, Polgar E. Calcium-binding proteins, parvalbuminand calbindin-D28k-immunoreactive neurons in the rat spinal cord and dorsal root ganglia: A light and electron microscopic study. J Comp Neurol. 1990;295:467-84.

20. Carr PA, Yamamoto T, Karmy G, Bainbridge KG, Nagy I. Analysis of parvalbumin and calbindin D28k-immunoreactive neurons in dorsal root ganglia of rat in relation to their cytochrome oxidase and carbonic anhydrase content. Neuroscience. 1989;33:363-71.

21. Celio MR. Calbindin-D28k and parvalbumin in the rat nervous system. Neuroscience. 1990;35:375-475.

22. Honda CN. Differential distribution of calbindin-D28k and parvalbumin in somatic and visceral sensory neurons. Neuroscience. 1995;68:883-92.

23. Ichikawa H, Deguchi T, Nakago T, Jacobowitz DM, Sugimoto T. Parvalbumin, calretinin and carbonic anhydrase in the trigeminal and spinal primary neurons of the rat. Brain Res. 1994;655:241-5.

24. Iino S, Kobayashi S, Hidaka H. Neurocalcin-immunopositive nerve terminals in the muscle spindle, Golgi tendon organ and motor endplate. Brain Res. 1998;808:294-9.

25. Szabolcs MJ, Kopp M, Schaden GE. Carbonic anhydrase activity in the peripheral nervous system of the rat: the enzyme as a marker for muscle afferents. Brain Res. 1989;492:129-38.

26. de Nooij JC, Doobar S, Jessell TM. Etv1 inactivation reveals proprioceptor sublclasses that refglect the level of NT3 expression in muscle targets. Neuron. 2013;77:1055-68.

27. Duc C, Barakat-Walker I, Droz B. Innervation of putative rapidly adapting mechanoreceptors by calbindin- and calretinin-immunoreactive primary sensory neurons in the rat. Eur J Neurosci. 1994;6:264-71.

28. Iino S, Kato M, Hidaka H, Kobayashi S. Neurocalcin-immunopositive neurons in the rat sensory ganglia. Brain Res. 1998;781:236-43.

29. Yang FC, Tan T, Huang T, Christianson J, Samad O, Liu Y, et al. Genetic control of the segregation of pain-related sensory neurons innervating cutaneous versus deep tissues. Cell Reports. 2013;5:1353-64.

30. Ichikawa H, Jin HW, Terayama S, Yamai T, Matsuo S, Sugimoto T. The reduction of proprioceptors in the mesencephalic trigeminal tract nucleus after neonatal masseteric nerve transection: effect of brain-derived neurotrophic factor. Brain Res. 2007;1153:98-102.

31. Wakisaka S, Takikita S, Youn SH, Kurisu K. Partial coexistence of neuropeptide $Y$ and calbindin-D28k in the trigeminal ganglion following peripheral axotomy of the inferior alveolar nerve in the rat. Brain Res. 1996;707:228-34.

32. Cao MH, Ji FT, Liu L, Li F. Expression changes of parvalbumin and microtubule associated protein 2 induced by chronic constriction injury in rat dorsal root ganglia. Chin Med J. 2011;124:2184-90.

33. Jamieson SM, Liu J, Connor B, McKeage MJ. Oxaliplatin causes selective atrophy of a subpopulation of dorsal root ganglion neurons without inducing cell loss. Cancer Chemother Pharmacol. 2005;56:391-9.

34. Fukuoka T, Yamanaka H, Kobayashi K, Okubo M, Miyoshi K, Dai Y, et al. Reevaluation of the phenotypic changes in L4 dorsal root ganglion neurons after L5 spinal nerve ligation. Pain. 2012;153:68-79.

35. Tsujino H, Kondo E, Fukuoka T, Dai Y, Tokunaga A, Miki K, et al. Activating transcription factor 3 (ATF3) induction by axotomy in sensory and motoneurons: a novel neuronal marker of nerve injury. Mol Cell Neurosci. 2000;15:170-82.
36. Kim SH, Chung JM. An experimental model for peripheral neuropathy produced by segmental spinal nerve ligation in the rat. Pain. 1992;50:355-63.

37. Patel TD, Kramer I, Kucera J, Niederkofler V, Jessell TM, Arber S, et al. Peripheral NT3 signalling is required for ETS protein expression and central patterning of proprioceptive sensory afferents. Neuron. 2003;38:403-16.

38. Pavel J, Hricová L, Jergová S, Lukáčová N. The impact of short-lasting repeated vibrations on retrograde axonal transport, the expression of CGRP and parvalbumin in lower lumbar dorsal root ganglia. Brain Res. 2011;1396:1-10.

39. Kirillova I, Rausch VH, Tode J, Baron R, Jänig W. Mechano- and thermosensitivity of injured muscle afferents. J Neurophysiol. 2011;105:2058-78.

40. Celio MR, Heizmann CW. Calcium-binding protein parvalbumin is associated with fast contracting muscle fibres. Nature. 1982;297:504-6.

41. Rall JA. Role of parvalbumin in skeletal muscle relaxation. News in Physiol Sci. 1996;11:249-55.

42. Carr PA, Yamamoto T, Karmy G, Bainbridge KG, Nagy I. Parvalbumin is highly colocalised with calbindin-D28k and rarely with calcitonin gene-related peptide in dorsal root ganglia neurons of rat. Brain Res. 1989;497:163-70.

43. Wakisaka S, Youn SH, Miyawaki Y, Kurisu K. The effects of peripheral nerve injury of the masseteric nerve on the levels of calcium binding proteins and neuropeptide $Y$, and their correlation in the mesencephalic trigeminal nucleus of the rat. Brain Res. 1996;735:249-56.

44. Ichikawa H, Jacobowitz DM, Sugimoto T. Coexpression of calretinin and parvalbumin in Ruffini-like endings in the rat incisor periodontal ligament. Brain Res. 1997;770:294-7.

45. Hammond DL, Ackerman L, Holdsworth R, Elzey B. Effects of spinal nerve ligation on immunohistochemically identified neurons in the L4 and L5 dorsal root ganglia of the rat. J Comp Neurol. 2004;475:575-89.

46. Averill S, Michael GJ, Shortland PJ, Priestley JV. NGF and GDNF ameliorate in the increase in ATF3 expression which occurs in dorsal root ganglion cells in response to peripheral nerve injury. Eur J Neurosci. 2004;19:1437-45.

47. Kataoka K, Kanje M, Dahlin LB. Induction of activating transcription factor 3 after different sciatic nerve injuries in adult rats. Scand J Plast Reconstr Hand Surg. 2007;41:158-66.

48. Hu P, McLachlan EM. Selective reactions of cutaneous and muscle afferent neurons to peripheral nerve transection in rats. J Neurosci. 2003;23(33):10559-67.

49. Gaudet AD, Williams SJ, Hwi LP, Ramer MS. Regulation of TRPV2 by axotomy in sympathetic, but not sensory neurons. Brain Res. 2004;1017:155-62.

50. Tsukagoshi M, Goris RC, Funakoshi K. Differential distribution of vanilloid receptors in the primary sensory neurons projecting to the dorsal skin and muscles. Histochem Cell Biol. 2011;126:343-52.

51. Peyronnard JM, Charron LF, Messier JP, Lavoie J. Differential effects of distal and proximal nerve lesions on carbonic anhydrase activity in rat primary sensory neurons, ventral and dorsal root axons. Exp Brain Res. 1998;70(3):550-60.

52. Shortland P, Wang HF, Molander C. Distribution of transganglionically labelled soybean agglutinin primary afferent fibres after nerve injury. Brain Res. 1999;815:206-12.

53. Shortland $\mathrm{P}$, Wang HF, Molander C. Transganglionic transport of the lectin soybean agglutinin (Glycine max) following injection into the sciatic nerve of the adult rat. J Neurocytol. 1998;27:233-45.

54. Kashiba H, Noguchi K, Ueda Y, Senba E. Neuropeptide $Y$ and galanin are coexpressed in rat large type A sensory neurons after peripheral transection. Peptides. 1992;15:411-6.

55. Michael GJ, Averill S, Shortland PJ, Yan Q, Priestley JV. Axotomy results in major changes in BDNF expression by dorsal root ganglion cells: BDNF expression in large trkB and trkC cells, in pericellular baskets, and in projections to deep dorsal horn and dorsal column nuclei. EurJ Neurosci. 1999;11:3539-51.

56. Fukuoka T, Miyoshi K, Noguchi K. De novo expression of Nav1.7 in injured putative proprioceptive afferents: multiple tetrodotoxin-sensitive sodium channels are retained in the rat dorsal root after spinal nerve ligation. Neuroscience. 2015;284:693-706.

57. Miki K, Fukuoka T, Tokunaga A, Noguchi K. Calcitonin gene-related peptide increase in the rat spinal dorsal horn and dorsal column nucleus 
following peripheral nerve injury: up-regulation in a subpopulation of primary afferent sensory neurons. Neuroscience. 1998;82:1243-52.

58. Noguchi K, Kawai Y, Fukuoka T, Senba E, Miki K. Substance P induced by peripheral nerve injury in primary afferent sensory neurons and its effect on dorsal column nucleus neurons. J Neurosci. 1995;15(11):7633-43.

59. Shehab SA. Fifth lumbar spinal nerve injury causes neurochemical changes in corresponding as well as adjacent spinal segments: a possible mechanism underlying neuropathic pain. J Chem Neuroanat. 2014;55:38-50.

60. Ikura M. Calcium binding and conformational response in EF-hand proteins. Trends in Biol Sci. 1996;21:4-17.

61. Yuan J, Yankner BA. Apoptosis in the nervous system. Nature. 2000;407:802-9.

62. Alexianu ME, Ho BK, Mohamed AH, La Bella V, Smith RG, Appel SH. The role of calcium binding proteins in selective motoneuron vulnerability in amyotrophic lateral sclerosis. Ann Neurol. 1994;36:846-58.

63. De La Cruz RR, Pastor AM, Martińez-Guijarro FJ, López-García C, DelgadoGarcía JM. Localization of parvalbumin, calretinin and calbindin D-28k in identified extraocular motoneurons and internuclear neurons of the cat. J Comp Neurol. 1998;390:377-91.

64. Ince P, Stout N, Shaw P, Slade J, Hunziker W, Heizmann CW, et al. Parvalbumin and calbindin D-28k in the human motor system and in motor neuron disease. Neuropath Appl Neurobiol. 1993;19:291-9.

65. Elliot JL, Snider WD. Parvalbumin is a marker of ALS-resistant motor neurons. NeuroReport. 1995;6:449-52.

66. Van Den Bosch L, Schwaller B, Vleminck V, Meijers B, Stork S, Ruehlicke $\mathrm{T}$, et al. Protective effect of parvalbumin on excitotoxic motor neuron death. Exp Neurol. 2002;174:50-161.

67. Lekan HA, Chung K, Yoon YW, Chung JM, Coggeshall RE. Loss of dorsal root ganglion cells concomitant with dorsal root axon sprouting following segmental nerve lesions. Neuroscience. 1997:81:527-34.

68. Tandrup T, Woolf CJ, Coggeshall RE. Delayed loss of small dorsal root ganglion cells after transection of the rat sciatic nerve. J Comp Neurol. 2000;422:172-80.
69. Englezou PC, Esposti MD, Wiberg M, Reid AJ, Terenghi G. Mitochondrial involvement in sensory neuronal cell death and survival. Exp Brain Res. 2012;221:357-67.

70. Reid AJ, Welin D, Wiberg M, Terenghi G, Novikov LN. Peripherin and ATF3 genes are differentially regulated in regenerating and non-regenerating primary sensory neurons. Brain Res. 2010;1310:1-7.

71. Welin D, Novikova LN, Wiberg M, Kellerth JO, Novikov LN. Survival and regeneration of cutaneous and muscular afferent neurons after peripheral nerve injury in adult rats. Exp Brain Res. 2008;186:315-23.

72. Pitts EV, Potlur S, Hess DM, Balice-Gordon RJ. Neurotrophin and Trkmediated signalling in the neuromuscular system. Intl Anaesthesiol Clin. 2006:44:21-76.

73. Wright DE, Williams JM, McDonald JT, Carlsten JA, Taylor MD. Musclederived neurotrophin-3 reduces injury-induced proprioceptive degeneration in neonatal mice. J Neurobiol. 2002;50:198-208.

74. Liu CN, Wall PD, Ben Dor E, Michaelis M, Amir R, Devor M. Tactile allodynia in the absence of c-fibre activation: altered firing properties of DRG neurons following spinal nerve injury. Pain. 2000;85:503-21.

75. Michaelis M, Liu X, Janig W. Axotomised and intact muscle afferents but no skin afferents develop ongoing discharges of dorsal root ganglion origin after peripheral nerve lesions. J Neurosci. 2000;20(7):2742-8.

76. Lever IJ, Bradbury EJ, Cunningham JR, Adelson DW, Jones MG, McMahon $\mathrm{SB}$, et al. Brain-derived neurotrophic factor is released in the dorsal horn by distinctive patterns of afferent fiber stimulation. J Neurosci. 2001;21(12):4469-77.

77. Pezet S, Malcangio M, McMahon SB. BDNF: a neuromodulator in nociceptive pathways? Brain Res Rev. 2002;40:240-9.

78. Zimmermann M. Ethical guidelines for investigations of experimental pain in conscious animals. Pain. 1983;16:109-10.

79. Leinster VLH, Robson LG, Shortland PJ. Differential effects of riluzole on subpopulations of adult rat dorsal root ganglion neurons in vitro. Neuroscience. 2010;166:942-51.

\section{Submit your next manuscript to BioMed Central and we will help you at every step:}

- We accept pre-submission inquiries

- Our selector tool helps you to find the most relevant journal

- We provide round the clock customer support

- Convenient online submission

- Thorough peer review

- Inclusion in PubMed and all major indexing services

- Maximum visibility for your research

Submit your manuscript at www.biomedcentral.com/submit
() Biomed Central 